\title{
Association of the Apolipoprotein E 2 Allele with Concurrent Occurrence of Endometrial Hyperplasia and Endometrial Carcinoma
}

\author{
Tatiana I. Ivanova, ${ }^{1,2}$ Ludmila I. Krikunova, ${ }^{1}$ Nikolay I. Ryabchenko, ${ }^{1}$ Liana S. Mkrtchyan, ${ }^{1}$ \\ Vera A. Khorokhorina, ${ }^{1}$ and Lyubov E. Salnikova ${ }^{3,4}$ \\ ${ }^{1}$ A. Cyb Scientific Centre of Radiology of the Hertsen Federal Medical Research Centre of the Ministry of Health of the Russian \\ Federation, 10 Zhukov Street, Obninsk, Kaluga Region 249036, Russia \\ ${ }^{2}$ Federal State Budget Institution of Sciences Institute of Gene Biology, Russian Academy of Sciences, 34/5 Vavilova Street, \\ Moscow 119334, Russia \\ ${ }^{3}$ Federal State Budget Institution of Sciences N.I. Vavilov Institute of General Genetics, Russian Academy of Sciences, 3 Gubkin Street, \\ Moscow 117971, Russia \\ ${ }^{4}$ Federal Research Center of Pediatric Hematology, Oncology and Immunology Named after Dmitry Rogachev, The Russian Ministry \\ of Health and Social Development, 1 Samora Machel Street, Moscow 117198, Russia
}

Correspondence should be addressed to Lyubov E. Salnikova; salnikovalyubov@gmail.com

Received 14 December 2014; Accepted 19 January 2015

Academic Editor: Liang-Jun Yan

Copyright (C) 2015 Tatiana I. Ivanova et al. This is an open access article distributed under the Creative Commons Attribution License, which permits unrestricted use, distribution, and reproduction in any medium, provided the original work is properly cited.

\begin{abstract}
Genes encoding proteins with antioxidant properties may influence susceptibility to endometrial hyperplasia (EH) and endometrial carcinoma (ECa). Patients with EH $(n=89)$, EH concurrent with ECa $(n=76)$, ECa $(n=186)$, and healthy controls $(n=1110)$ were genotyped for five polymorphic variants in the genes involved in metabolism of lipoproteins (APOE Cys112Arg and Arg158Cys), iron (HFE Cys282Tyr and His63Asp), and catecholamines (COMT Val158Met). Patients and controls were matched by ethnicity (all Caucasians), age, body mass index (BMI), and incidence of hypertension and diabetes. The frequency of the APOE E 2 allele (158Cys) was higher in patients with EH + ECa than in controls $\left(P=0.0012, P_{\text {Bonferroni }}=0.018, \mathrm{OR}=2.58,95 \%\right.$ CI 1.49-4.45). The APOE E 4 allele (112Arg) was more frequently found in patients with $\mathrm{EH}$ than in controls and HFE minor allele G (63Asp) had a protective effect in the ECa group, though these results appeared to be nonsignificant after correction for multiple comparisons. The results of the study indicate that E 2 allele might be associated with concurrent occurrence of EH and ECa.
\end{abstract}

\section{Introduction}

Cancer of the endometrium is the most common gynecologic malignancy in developed countries and the second most common in developing countries [1]. Most cases (75-85\%) of endometrial carcinoma occur in the sixth and seventh decades of life, and $95 \%$ occur in patients over 40 years of age $[2,3]$. In general, endometrial carcinoma tends to have a favorable prognosis, but it is still a life-threatening disease. A number of deaths from endometrial cancer in the United States doubled between 1988 and 1998, probably due to an increase in life expectancy and high prevalence of obesity, diabetes, and hypertension, which predispose to this disease [4]. Amongst all cancers, endometrial cancer has the strongest association with obesity [5], a state characterized by chronic oxidative stress [6]. Adipocytes and inflammatory cells from visceral adipose tissue depots produce adipokines and cytokines which promote tumor development. Adipocyte mediated conversion of androgens to estrogen can add high risk to the development of endometrial cancer [7]. Associated with aging oxidative stress occurs in many tissues whose sensitivity to reactive oxygen species (ROS) appears to arise with increasing age $[8,9]$.

Not all females exposed to the same risk factors will develop an endometrial cancer. Although the most common types of endometrial cancer (e.g., endometrioid carcinoma) 
often develop from the endometrial hyperplasia, the latter will not necessarily progress to malignancy. An individual's susceptibility to disease development and progression is influenced by genetics. A few case-control studies have investigated the correlation of single nucleotide polymorphisms (SNPs) with hyperplasia of endometrium alone or in combination with endometrial cancer. It was shown that variant alleles of the CYP1A1 and CYP17 genes might be associated with endometrial hyperplasia $(\mathrm{EH})$ and endometrial adenocarcinoma (ECa) susceptibility $[10,11]$. Morosova et al. found that $M M P 1$ variant may be a risk marker of myo- and endometrial hyperplasia [12]. The results of these assays suggest that identification of genetic risk factors may provide a screening tool to reveal individuals at increased risk of development of hyperplasia and its progression to endometrial cancer. The present study examines the role of functional genetic polymorphisms in the genes encoding enzymes with the antioxidant properties being involved in metabolism of lipoproteins (APOE), iron (HFE), and catecholamines $(C O M T)$ in patients with $\mathrm{EH}, \mathrm{EH}$ concurrent with ECa, and ECa without $\mathrm{EH}$.

\section{Materials and Methods}

2.1. Patients and Controls. From August 2006 to August 2014 we selected a group of hospitalized and ambulatory patients with EH, ECa, and controls at A. Cyb Scientific Centre of Radiology of the Hertsen Federal Medical Research Centre of the Ministry of Health of the Russian Federation. A total of 1461 females from the European region of Russian Federation were recruited in the study. The study group consisted of 89 patients with histologically diagnosed simple $\mathrm{EH}$ (according to the endometrial intraepithelial neoplasia (EIN) nomenclature; [13]), 76 patients with ECa and EH, and 186 patients with ECa without hyperplasia. Exclusion criteria for the group under study consisted of age less than 18 years, lack of written informed consent, and previous history of any type of cancer. Females with EIN, adenomyosis, endometriosis, and types of cancer other than ECa (e.g., uterine sarcoma) were excluded. The patients were diagnosed as having ECa and EH by fractional endometrial biopsy. Total hysterectomy, bilateral pelvic and para-aortic lymphadenectomy, and omentectomy were performed in ECa patients. All cases were microscopically verified. The tumors were staged according to the International Federation of Gynecology and Obstetrics (FIGO) classification [14]. The study protocol was approved by the Ethics Committee of A. Cyb Scientific Centre of Radiology of the Hertsen Federal Medical Research Centre of the Ministry of Health of the Russian Federation and adhered to the tenets of the Declaration of Helsinki.

2.2. Genotyping. DNA was extracted from $500 \mu \mathrm{L}$ of whole blood using Wizard Genomic DNA Purification Kit (Promega, Madison, WI, USA). Genotypes were determined by a PCR-based restriction fragment length polymorphism (RFLP) technique. The $310 \mathrm{bp}$ fragment of the $A P O E$ gene exon 4 which contains both polymorphic codons (Cys282Tyr and His63Asp) was amplified using primers $\mathrm{F} 5^{\prime}$-GAGACGCGGGCACGGCTGTCC and $\mathrm{R}$ $5^{\prime}$-GCACGCGGCCCTGTTCCACC. The $389 \mathrm{bp}$ fragment of the HFE gene including codon Cys282Tyr was amplified with primers $\mathrm{F} 5^{\prime}$-TGGCAAGGGTAAACAGATCC and R $5^{\prime}$-CTCAGGCACTCCTCTCAACC; the $208 \mathrm{bp}$ fragment of the HFE gene containing codon His63Asp was amplified using primers $\mathrm{F} 5^{\prime}$-ACATGGTTAAGGCCTGTTGC and R 5'-GCCACATCTGGCTTGAAATT. Primers used to amplify a $169 \mathrm{bp}$ of the COMT gene containing codon Vall58Met were $\mathrm{F} 5^{\prime}$-ACTGTGGCTACTCAGCTGTG and R $5^{\prime}$-CCTTTTTCCAGGTCTGACAA [15]. The fragments were amplified in $25 \mu \mathrm{L}$ reaction volume containing $0,625 \mathrm{U}$ of HotStarTag polymerase (Qiagen, Valencia, USA), 0,15 mM dNTPs, $0,2 \mu \mathrm{M}$ primers, and $50 \mathrm{ng}$ of genomic DNA. PCR-reactions were carried out as follows: at first $15 \mathrm{~min}$ denaturing at $95^{\circ} \mathrm{C}$ and then 30 amplification cycles $(30 \mathrm{~s}$ at $94^{\circ} \mathrm{C}, 30 \mathrm{~s}$ at $67^{\circ} \mathrm{C}, 1 \mathrm{~min}$ at $72^{\circ} \mathrm{C}$ ) for $A P O E ; 30$ cycles $\left(30 \mathrm{~s}\right.$ at $94^{\circ} \mathrm{C}, 1 \mathrm{~min}$ at $60^{\circ} \mathrm{C}, 30 \mathrm{~s}$ at $72^{\circ} \mathrm{C}$ ) for $\mathrm{HFE}$; and 40 cycles $\left(30 \mathrm{~s}\right.$ at $94^{\circ} \mathrm{C}, 1 \mathrm{~min}$ at $57^{\circ} \mathrm{C}, 30 \mathrm{~s}$ at $72^{\circ} \mathrm{C}$ ) for COMT. A final extension of $10 \mathrm{~min}$ at $72^{\circ} \mathrm{C}$ was then applied for all reactions. Amplified fragments were digested with either Rsa I (Promega, Madison, WI, USA) or BclI (SIGMA, Saint Louis, MO, USA) for detection of the Cys282Tyr or His63Asp of the HFE gene; Cfo (Promega, Madison, WI, USA) for the APOE genotype determination and Hsp92II (Promega, Madison, WI, USA) for the Val158Met of the COMT gene. Digests were performed according to the manufacturer's instructions. PCR products and digested fragments were run on $8 \%$ polyacrylamide gels, stained with ethidium bromide, and visualized by UV. For quality controls, $10 \%$ of random samples of DNA were genotyped twice and the results were concordant for all duplicated sets.

2.3. Statistical Analysis. Deviation from Hardy-Weinberg equilibrium (HWE) was assessed by $\chi^{2}$ analysis. Two-tailed Fisher's exact test (implemented in the WINPEPI computer programs; module A in COMPARE2 package [16]) was performed to evaluate differences between clinical and tumor characteristics of patients. The distributions of genotypes and haplotypes in cases and controls were compared using a logistic regression analysis, implemented in SNPStats package [17]. SNPStats is a free web-based tool for genetic association studies. The association with disease is modeled with unconditional logistic regression. In the analysis of the SNPs in relation to the response, SNPStats provides odds ratios (ORs), the confidence interval (CI), the $P$ values for multiple inheritance models (dominant (var/var and wt/var versus wt/wt), recessive (var/var versus wt/var and wt/wt), overdominant (wt/var versus wt/wt and var/var), codominant (wt/wt versus wt/wt; wt/var versus wt/var; var/var versus var/var), and additive (wt allele versus var allele)), and the Akaike Information Criterion (AIC) indicating the best genetic model for each SNP. In multivariate models, quantitative or categorical variables may be additionally included in the regression models to be considered as potential confounders. Multivariate models predict outcomes that are affected by more than one variable. In multivariate models, we adjusted for age, body mass index (BMI), hypertension, 
TABLE 1: Clinical characteristics in patients and controls.

\begin{tabular}{|c|c|c|c|c|c|c|c|}
\hline \multirow[b]{2}{*}{ Characteristics } & \multirow{2}{*}{$\begin{array}{c}\text { Controls }(N=1110) \\
N(\%) \\
\text { Mean } \pm \text { SD }\end{array}$} & \multicolumn{2}{|c|}{$\mathrm{EH}(N=89)$} & \multicolumn{2}{|c|}{$\mathrm{EH}+\mathrm{ECa}(N=76)$} & \multicolumn{2}{|c|}{$\mathrm{ECa}(N=186)$} \\
\hline & & $\begin{array}{c}N(\%) \\
\text { Mean } \pm \text { SD }\end{array}$ & $P$ & $\begin{array}{c}N(\%) \\
\text { Mean } \pm \text { SD }\end{array}$ & $P$ & $\begin{array}{c}N(\%) \\
\text { Mean } \pm \text { SD }\end{array}$ & $P$ \\
\hline Age (years) & $59.96 \pm 12.17$ & $58.69 \pm 10.20$ & 0.32 & $57.90 \pm 10.61$ & 0.14 & $58.60 \pm 9.62$ & 0.13 \\
\hline BMI $\left(\mathrm{kg} / \mathrm{m}^{2}\right)$ & $29.44 \pm 5.30$ & $28.58 \pm 5.79$ & 0.14 & $30.09 \pm 9.00$ & 0.33 & $30.04 \pm 7.25$ & 0.18 \\
\hline Smoking & $122(10.99)$ & $6(6.74)$ & 0.28 & $4(5.26)$ & 0.17 & $11(5.91)$ & 0.036 \\
\hline Hypertension & $426(38.38)$ & 35 (39.33) & 0.91 & $34(44.74)$ & 0.28 & $80(43.01)$ & 0.26 \\
\hline Diabetes & $39(3.51)$ & $1(1.12)$ & 0.36 & $6(7.89)$ & 0.062 & $12(6.45)$ & 0.066 \\
\hline HRT & $221(19.91)$ & $16(17.98)$ & 0.78 & $14(18.42)$ & 0.88 & $19(10.22)$ & 0.001 \\
\hline
\end{tabular}

Significant results are in bold.

diabetes, smoking habits, and using of hormone replacement therapy (HRT). For the regression models we present OR for the minor allele. The best genetic model was selected using the AIC value. The lowest AIC value was considered the bestfitting model for the fitted variant. For genotypes with minor allele frequencies $<10 \%$ only dominant and additive genetic models were considered.

To exclude the false-positive associations, we used Bonferroni correction for multiple comparisons. To perform correction for multiplicity we divided the critical $P$ value by the number of comparisons being made ( 5 SNPs and three groups of cases; 15 comparisons). The cut-off $P$ value was $0.05 / 15=0.0033$. When we considered $A P O E$ reference genotype $3 / 3$ in comparison with all other $A P O E$ genotypes, significant $P$ value was set at $0.05 / 12=0.0041$.

WINPEPI test power and sample size calculators (in COMPARE2 package) were used to evaluate type II error [16]. The statistical power of association studies strongly depends on the sample size, genetic model, and genotype frequencies [18]. An effect size of 2.0 and higher is thought to be clinically meaningful [19]. To detect $\mathrm{OR}=2.00$ for minor allele frequencies 0.10 and 0.25 in our sample size, the power ranges from $41.19 \%$ to $81.24 \%$ and from $73.10 \%$ to $97.88 \%$, respectively. Post hoc power calculations showed that, for a main effect, statistical power was $88.43 \%$ (EH + ECa group, APOE rs7412, OR = 2.58).

\section{Results}

3.1. Characteristics of the Study Population. Clinicodemographic characteristics of the group under study are presented in Table 1. Patients and controls were matched by ethnicity (all Caucasians), age, and BMI. There were no differences between the study groups in relation to hypertension and diabetes incidence. With the exception of the group ECa, the frequencies of smoking (ever smoking versus never smoking) did not differ between patients and controls. Striking contrast was found between groups under study in relation to ever use of HRT. In controls, EH, and EH + ECa groups, $20 \%, 18 \%$, and $18 \%$ of females used HRT, while in the ECa group, only $10 \%$ of females took HRT $(P=0.001)$.

Tumor characteristics of patients are given in Table 2. EH + ECa patients had a more favorable stage and grade than ECa patients. For example, 92.11\% EH + ECa patients were
TABLE 2: Tumor characteristics of patients with ECa.

\begin{tabular}{lccc}
\hline Characteristics & $\begin{array}{c}\text { EH }+ \text { ECa } \\
(n=76)\end{array}$ & $\begin{array}{c}\text { ECa } \\
\text { Histopathologic grades }\end{array}$ & \\
& $N(\%)$ & $N(\%)$ & \\
G1 (well differentiated) & $34(44.74)$ & $48(25.81)$ & $\mathbf{0 . 0 0 3}$ \\
G2 (moderately differentiated) & $28(36.84)$ & $97(52.15)$ & $\mathbf{0 . 0 2 9}$ \\
G3 (poorly or undifferentiated) & $7(9.21)$ & $8(4.30)$ & 0.14 \\
Gx (N/A) & $7(9.21)$ & $33(17.74)$ & 0.091 \\
\hline \multicolumn{4}{c}{ Histopathologic types (WHO/ISGP) } \\
Endometrioid adenocarcinoma & $71(93.42)$ & $150(80.65)$ & $\mathbf{0 . 0 0 9}$ \\
Clear cell adenocarcinoma & $4(5.26)$ & $1(0.54)$ & $\mathbf{0 . 0 2 6}$ \\
Adenosquamous carcinoma & 0 & $2(1.08)$ & - \\
Papillary serous adenocarcinoma & $1(1.32)$ & $8(4.30)$ & 0.45 \\
x (N/A) & 0 & $25(13.44)$ & - \\
\hline \multicolumn{4}{c}{ FIGO stages } \\
I & $67(88.16)$ & $131(70.43)$ & $\mathbf{0 . 0 0 2}$ \\
II & $3(3.95)$ & $30(16.13)$ & $\mathbf{0 . 0 0 7}$ \\
III & $2(2.63)$ & $13(6.99)$ & 0.24 \\
IV & $2(2.63)$ & $3(1.61)$ & 0.63 \\
X (N/A) & $2(2.63)$ & $9(4.84)$ & 0.52 \\
\hline N/A not avain
\end{tabular}

N/A: not available. Significant results are in bold.

FIGO I-II stages and $81.58 \%$ G1-2 grades (well and moderately differentiated). In the ECa group, FIGO I-II stages and G1-2 grades had $86.56 \%$ and $77.96 \%$ of subjects, respectively.

3.2. Genetic Associations of Selected Candidate Genes in EH, $E H+E C a$, and $E C a$ Studies. The genotype distributions of the COMT (Val158Met), HFE (Cys282Tyr and His63Asp), and APOE (Cys112Arg and Arg158Cys) polymorphisms between cases and healthy controls are shown in Table 3 . With the exception for the HFE rs1799945 in the ECa group, the genotype frequencies of the polymorphisms in controls and cases were consistent with the Hardy-Weinberg equilibrium distribution. A significant increase in the frequency of the $\mathrm{E} 2$ allele (APOE rs7412-T, 158Cys) was observed in patients with $\mathrm{EH}+\mathrm{ECa}$ compared with controls in both crude $\left(P=2.6 \times 10^{-5}, P_{\text {Bonferroni }}=3.9 \times 10^{-4}, \mathrm{OR}=3.12,95 \%\right.$ 


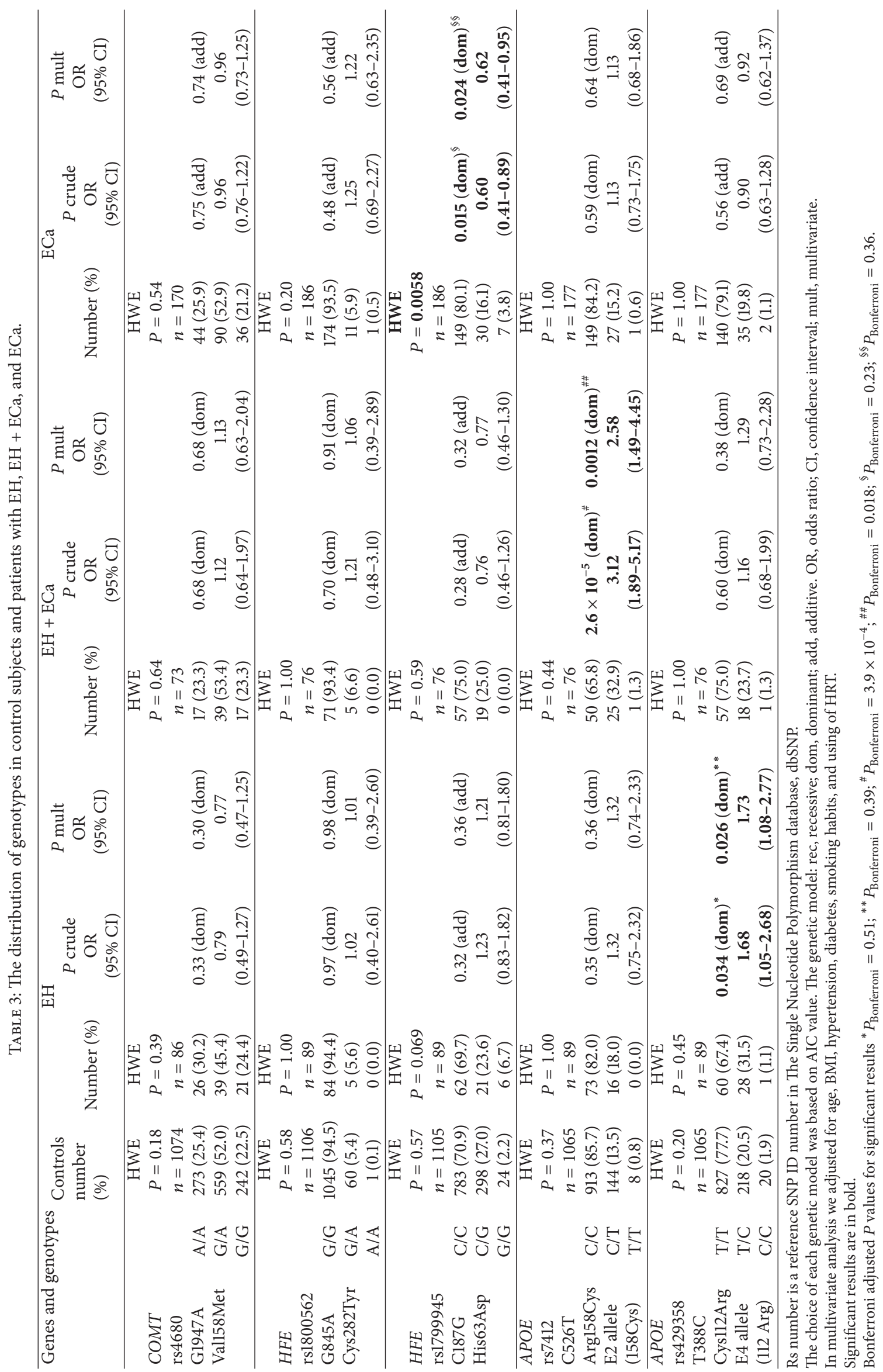


CI 1.89-5.17) and multivariate analyses $\left(P=0.0012, P_{\text {Bonferroni }}\right.$ $=0.018, \mathrm{OR}=2.58,95 \% \mathrm{CI} 1.49-4.45)$. Though nonsignificant after Bonferroni correction for multiple comparisons, the $\mathrm{E} 4$ allele (APOE rs429358-C, 112Arg) was more frequently found in patients with $\mathrm{EH}$ than in controls and HFE rs1799945 minor allele $\mathrm{G}$ had a protective effect in the ECa group.

To further exploit the role of APOE E 2 allele in concurrent occurrence of $\mathrm{EH}$ and $\mathrm{ECa}$, we performed an additional study of clinicodemographic characteristics in relation to different $A P O E$ alleles. In patients with $\mathrm{EH}+\mathrm{ECa}, \mathrm{E} 2$ allele was not associated with BMI, hypertension, diabetes, smoking habits, and HRT (Table 4) or with different tumor grades (G1 versus G2-3) (Table 5).

Next, we employed the distribution of the APOE reference E 3/E 3 (112Cys-158Arg/112Cys-158Arg) and variant genotypes in controls and cases (Table 6). The effects appeared to be less pronounced: variant genotypes (all together) were associated with $\mathrm{EH}\left(P=0.038, P_{\text {Bonferroni }}>0.05, \mathrm{OR}=1.60\right.$, $95 \% \mathrm{CI} 1.04-2.47)$ and $\mathrm{EH}+\mathrm{ECa}\left(P=0.004, P_{\text {Bonferroni }}=\right.$ 0.048, OR $=1.98,95 \%$ CI 1.24-3.15).

In the overall cancer group (EH + ECa and $\mathrm{ECa}), A P O E$ E 2 allele was more frequent among patients compared with controls, but the results were nonsignificant after multiple testing corrections $\left(P=0.036, P_{\text {Bonferroni }}>0.05, \mathrm{OR}=1.54\right.$, 95\% CI 1.03-2.30).

Haplotype analysis of the HFE gene polymorphisms was undertaken and the estimated haplotype frequencies are presented in Table 7 . No significant differences were observed between controls and patients in any group in regard to haplotype frequencies. Haplotype comprising both minor alleles rs1800562-A/rs1799945-G was not found in our sample.

\section{Discussion}

In this study of five polymorphisms in antioxidant-related genes (two each in $A P O E$ and $H F E$, one in COMT), we found that $A P O E \mathrm{E} 2$ allele (158Cys) was associated with a concurrent occurrence of $\mathrm{EH}$ and $\mathrm{ECa}$ in a cohort of Caucasian patients from the European region of Russian Federation. The APOE E 4 allele (112Arg) was more frequently found in patients with $\mathrm{EH}$ than in controls and HFE minor allele $\mathrm{G}$ (63Asp) had a protective effect in the ECa group. Only the effect of the APOE E 2 allele in $\mathrm{EH}+\mathrm{ECa}$ patients appeared to be significant after correction for multiple testing procedures.

Endometrial carcinoma may arise and evolve through divergent pathways and different precursor lesions. Based on histopathology and molecular alterations, endometrial cancers are divided into two major pathogenetic variants [20]. The first pathogenetic variant comprises low-grade (G1-2) adenocarcinomas that are typically diagnosed early, are usually estrogen dependent, and have a favorable prognosis. The pathway of this variant of adenocarcinoma includes several steps: simple hyperplasia, atypical hyperplasia, and endometrial carcinoma [20]. The second pathogenetic variant comprises adenocarcinomas that are not hormone dependent and are usually grade 3 (G3) tumors that are associated with early
TABLE 4: The distributions of BMI, hypertension, diabetes, smoking habits, and HRT in patients with $\mathrm{EH}+\mathrm{ECa}$ with different APOE E2 genotypes.

\begin{tabular}{lccc}
\hline Characteristics & $\begin{array}{c}\mathrm{C} / \mathrm{C}(n=50) \\
\text { Number } \\
\text { Mean } \pm \text { SD }\end{array}$ & $\begin{array}{c}\text { C/T-T/T }(n=26) \\
\text { Number } \\
\text { Mean } \pm \text { SD }\end{array}$ & $P$ value \\
\hline Age (years) & $56.90 \pm 11.11$ & $59.82 \pm 9.49$ & 0.26 \\
BMI $\left(\mathrm{kg} / \mathrm{m}^{2}\right)$ & $30.56 \pm 8.93$ & $29.18 \pm 9.14$ & 0.53 \\
Smoking & 2 & 2 & 0.60 \\
Hypertension & 24 & 10 & 0.47 \\
Diabetes & 5 & 1 & 0.66 \\
HRT & 10 & 4 & 0.76 \\
\hline
\end{tabular}

spread and worse prognosis. It is assumed that the second pathogenetic variant of adenocarcinomas can arise from dedifferentiation of a preexisting first pathogenetic variant of cancer [21]. Though considered benign, simple endometrial hyperplasia is followed by ECa in 19\% of the cases; complex hyperplasia with atypia is recognized as an early malignant lesion and occurs concurrently with ECa in 39\% of the cases [22]. In general, tumor features of our groups under study are in line with the above characteristics. There are more cases with lower grades and FIGO stages in the group with the concurrent occurrence of hyperplasia and adenocarcinoma than in the group with adenocarcinoma only. Compared to the ECa cases, females with EH + ECa were the more frequent users of HRT, which may be associated with the increased risk of estrogen-related endometrial cancer.

APOE is one of the major plasma lipoproteins with antioxidant, anti-inflammatory, and antiatherogenic properties [23]. APOE is presented in multiple normal and cancer tissues, including normal human endometrium [24], EH, and ECa $[25,26]$. It is upregulated in many types of human cancer: ovarian [27, 28], pancreatic [29], prostate [30], gastric $[31,32]$, and anaplastic thyroid cancer [33] and glioblastoma [34]. In gastric cancer, anaplastic thyroid carcinoma, and poorly differentiated endometrial adenocarcinoma, APOE overexpression was associated with advanced grade and stage or more aggressive low differentiated tumors [26, 31, 33]. Upregulation of APOE precursor was observed also in simple endometrial hyperplasia [35]. In vivo experiments in hamsters have shown that overexpression of Apoe may play significant role in the malignant transformation of oral mucosa precancerous lesions to squamous cell carcinoma [36]. Increased APOE expression in hyperplasia and cancer are not fully understood. APOE may be involved in signal transduction and lipid transport essential for proliferation and survival of tumor cells or may potentiate tumor proliferation and survival maintaining a specific microenvironment [28]. Apolipoprotein E is also produced in macrophages [37]. Tumor-associated macrophages (TAMs) have been shown to relate to vascular space invasion and myometrial invasion in ECa [38]. TAMs are also involved in progression of precancerous endometrial lesions in ECa [39].

APOE isoforms differ in amino acid residues at positions 112 and 158. E 3, the most common isoform, contains cysteine 
TABLE 5: The distribution of genotypes in patients with $\mathrm{EH}+\mathrm{ECa}$ with different tumor grades.

\begin{tabular}{|c|c|c|c|c|c|}
\hline \multicolumn{2}{|c|}{ Genes and genotypes } & $\begin{array}{l}\text { Grade I (G1) } \\
\text { Number (\%) }\end{array}$ & $\begin{array}{c}\text { Grade II-III (G2-3) } \\
\text { Number (\%) }\end{array}$ & $\begin{array}{c}P \text { crude OR } \\
(95 \% \text { CI })\end{array}$ & $\begin{array}{c}P \text { mult OR } \\
(95 \% \mathrm{CI})\end{array}$ \\
\hline \multirow{4}{*}{$\begin{array}{l}\text { COMT } \\
\text { rs4680 } \\
\text { G1947A } \\
\text { Val158Met }\end{array}$} & & $n=34$ & $n=29$ & & \\
\hline & $\mathrm{G} / \mathrm{G}$ & $9(26.47)$ & $8(27.6)$ & $0.34(\mathrm{rec})$ & $0.34(\mathrm{rec})$ \\
\hline & G/A & $19(55.88)$ & $14(48.3)$ & 1.78 & 1.81 \\
\hline & $\mathrm{A} / \mathrm{A}$ & $6(17.65)$ & $7(24.1)$ & $(0.54-5.90)$ & $(0.54-6.10)$ \\
\hline \multirow{4}{*}{$\begin{array}{l}\text { HFE } \\
\text { rs1800562 } \\
\text { G845A } \\
\text { Cys282Tyr }\end{array}$} & & $n=34$ & $n=31$ & & \\
\hline & $\mathrm{G} / \mathrm{G}$ & $32(94.1)$ & $28(90.3)$ & 0.57 (dom) & $0.52(\mathrm{dom})$ \\
\hline & $\mathrm{G} / \mathrm{A}$ & $2(5.9)$ & $3(9.7)$ & 1.71 & 1.85 \\
\hline & $\mathrm{A} / \mathrm{A}$ & $0(0.0)$ & $0(0.0)$ & $(0.27-11.01)$ & $(0.28-12.42)$ \\
\hline \multirow{4}{*}{$\begin{array}{l}\text { HFE } \\
\text { rs1799945 } \\
\text { C187G } \\
\text { His63Asp }\end{array}$} & & $n=34$ & $n=31$ & & \\
\hline & $\mathrm{C} / \mathrm{C}$ & $28(82.3)$ & $21(67.7)$ & $0.17(\mathrm{dom})$ & 0.14 (dom) \\
\hline & $\mathrm{C} / \mathrm{G}$ & $6(17.6)$ & $10(32.3)$ & 2.22 & 2.48 \\
\hline & $\mathrm{G} / \mathrm{G}$ & $0(0.0)$ & $0(0.0)$ & $(0.70-7.09)$ & $(0.73-8.44)$ \\
\hline \multirow{4}{*}{$\begin{array}{l}\text { APOE } \\
\text { rs7412 } \\
\text { C526T } \\
\text { Arg158Cys (E2 allele) }\end{array}$} & & $n=34$ & $n=31$ & & \\
\hline & $\mathrm{C} / \mathrm{C}$ & $19(55.9)$ & $23(74.2)$ & $0.12(\mathrm{dom})$ & 0.10 (dom) \\
\hline & $\mathrm{C} / \mathrm{T}$ & $14(41.2)$ & $8(25.8)$ & 0.44 & 0.40 \\
\hline & $\mathrm{T} / \mathrm{T}$ & $1(2.9)$ & $0(0.0)$ & $(0.15-1.26)$ & $(0.13-1.22)$ \\
\hline \multirow{4}{*}{$\begin{array}{l}\text { APOE } \\
\text { rs429358 } \\
\text { T388C } \\
\text { Cys112Arg (E4 allele) }\end{array}$} & & $n=34$ & $n=31$ & & \\
\hline & $\mathrm{T} / \mathrm{T}$ & $28(82.3)$ & $20(64.5)$ & 0.10 (dom) & 0.097 (dom) \\
\hline & $\mathrm{T} / \mathrm{C}$ & $5(14.7)$ & $11(35.5)$ & 2.57 & 2.61 \\
\hline & $\mathrm{C} / \mathrm{C}$ & $1(2.9)$ & $0(0.0)$ & $(0.81-8.09)$ & $(0.82-8.29)$ \\
\hline
\end{tabular}

The choice of each genetic model was based on AIC value. The genetic model: rec, recessive; dom, dominant. OR, odds ratio; CI, confidence interval; mult, multivariate.

In multivariate analysis we adjusted for age, BMI, hypertension, diabetes, smoking habits, and using of HRT.

TABLE 6: The distribution of the APOE E 3/E 3 reference and variant (including E 2 and $\mathrm{E} 4$ alleles) genotypes in control subjects and patients with $\mathrm{EH}, \mathrm{EH}+\mathrm{ECa}$, and $\mathrm{ECa}$.

\begin{tabular}{|c|c|c|c|c|c|c|c|c|}
\hline \multirow{2}{*}{\multicolumn{2}{|c|}{ APOE genotypes }} & \multirow{2}{*}{$\begin{array}{l}\text { Controls } \\
\text { number (\%) }\end{array}$} & \multicolumn{2}{|c|}{$\mathrm{EH}$} & \multicolumn{2}{|c|}{$\mathrm{EH}+\mathrm{ECa}$} & \multicolumn{2}{|c|}{$\mathrm{ECa}$} \\
\hline & & & Number (\%) & $\begin{array}{c}P \text { mult } \\
\text { OR }(95 \% \mathrm{CI})\end{array}$ & Number (\%) & $\begin{array}{c}P \text { mult } \\
\text { OR }(95 \% \mathrm{CI})\end{array}$ & Number (\%) & $\begin{array}{c}P \text { mult OR } \\
(95 \% \mathrm{CI})\end{array}$ \\
\hline \multirow{3}{*}{ rs7412 + rs429358 } & & $n=1065$ & $n=89$ & $0.038^{*}$ & $n=76$ & $0.004^{* *}$ & $n=177$ & 0.87 \\
\hline & E $3 /$ E 3 & $695(65.26)$ & $48(53.93)$ & 1.60 & $37(48.68)$ & 1.98 & $114(64.41)$ & 1.04 \\
\hline & Other & $370(34.74)$ & $41(46.07)$ & $(1.04-2.47)$ & $39(51.32)$ & $(1.24-3.15)$ & $63(35.39)$ & $(0.75-1.45)$ \\
\hline
\end{tabular}

APOE E 3 allele, 112Cys, and 158Arg; other, any genotypes with 112Arg and/or 158Cys.

OR, odds ratio; $\mathrm{CI}$, confidence interval; mult, multivariate.

In multivariate analysis we adjusted for age, BMI, hypertension, diabetes, smoking habits, and using of HRT. Significant results are in bold.

Bonferroni adjusted $P$ values ${ }^{*} P_{\text {Bonferroni }}=0.46 ;{ }^{* *} P_{\text {Bonferroni }}=0.048$.

TABLE 7: Haplotype-based analysis of the HFE gene polymorphisms in EH, EH + ECa, and ECa.

\begin{tabular}{|c|c|c|c|c|c|c|c|c|c|}
\hline \multirow[b]{2}{*}{$N$} & \multirow[b]{2}{*}{$\begin{array}{l}\text { rs1800562 } \\
\text { G845A }\end{array}$} & \multirow[b]{2}{*}{$\begin{array}{l}\text { rs1799945 } \\
\text { C187G }\end{array}$} & \multirow{2}{*}{$\begin{array}{l}\text { Controls } \\
\text { frequency } \\
(\%)\end{array}$} & \multicolumn{2}{|c|}{$\mathrm{EH}(n=1195)^{*}$} & \multicolumn{2}{|c|}{$\mathrm{EH}+\mathrm{ECa}(n=1182)^{*}$} & \multicolumn{2}{|c|}{$\mathrm{EC}(n=1292)^{*}$} \\
\hline & & & & $\begin{array}{l}\text { Frequency } \\
(\%)\end{array}$ & $\begin{array}{c}P \text { mult } \\
\text { OR }(95 \% \mathrm{CI})\end{array}$ & $\begin{array}{c}\text { Frequency } \\
(\%)\end{array}$ & $\begin{array}{c}P \text { mult } \\
\text { OR }(95 \% \mathrm{CI})\end{array}$ & $\begin{array}{l}\text { Frequency } \\
(\%)\end{array}$ & $\begin{array}{c}P \text { mult } \\
\text { OR }(95 \% \mathrm{CI})\end{array}$ \\
\hline 1 & G & $\mathrm{C}$ & 0.8154 & 0.7928 & Reference & 0.8421 & Reference & 0.8468 & Reference \\
\hline 2 & G & G & 0156 & 0.1791 & $\begin{array}{c}0.35 \\
1.21(0.81-1.80)\end{array}$ & 0.125 & $\begin{array}{c}0.33 \\
0.77(0.45-1.30)\end{array}$ & 0.1183 & $\begin{array}{c}0.15 \\
0.77(0.53-1.10)\end{array}$ \\
\hline 3 & A & $\mathrm{C}$ & 0.028 & 0.0218 & $\begin{array}{c}0.97 \\
1.02(0.40-2.58)\end{array}$ & 0.0329 & $\begin{array}{c}0.98 \\
0.99(0.38-2.59)\end{array}$ & 0.0349 & $\begin{array}{c}0.62 \\
1.18(0.61-2.28)\end{array}$ \\
\hline
\end{tabular}

OR, odds ratio; CI, confidence interval; mult, multivariate.

${ }^{*}$ The number of subjects with both genotyped SNPs. Subjects with missing genotyping data for one of the SNPs were not included in the haplotype-based analysis.

In multivariate analysis we adjusted for age, BMI, hypertension, diabetes, smoking habits, and using of HRT. 
and arginine at these codons; $\mathrm{E} 2$ has two cysteines and $\mathrm{E} 4$ two arginines. E 2 is characterized by a $50-100$-fold weaker binding affinity of the protein for cell surface LDL receptors that leads to type III hyperlipoproteinaemia, that is, high circulating triglycerides (TAG) levels. It is assumed that E 2 has the greatest stability and least formation of intermediate metabolites. Amino acid substitution resulting in $\mathrm{E} 4$ isoform effects chemical and thermal stability through conformation changes and reveals better lipid binding activity [40]. Isoforms exhibit the differential lipoprotein binding preferences. E 2 and E 3 prefer interaction with small lipoproteins such as HDL, while $\mathrm{E} 4$ more frequently binds to larger lipid-rich lipoproteins (very-low-density lipoprotein, VLDL, and lowdensity lipoprotein, LDL). E 2 has a potential beneficial effect on lipid profile, especially total cholesterol (TC) and lowdensity lipoprotein-cholesterol (LDL-C) levels; however, E 2 carriers have higher BMI, waist circumference, homeostasis model insulin resistance index, triglyceride/high density lipoprotein-cholesterol ratio, and increased risk of metabolic syndrome. APOE E 4 is associated with increased serum triglyceride (TG), TC and LDL-C levels [41], and the diseases with known or proposed association with oxidative stress and a proinflammatory status, for example, coronary heart disease and stroke [42], Alzheimer's disease [43], and psoriasis [44].

Oxidative stress is recognized to be involved in many disorders of the female reproductive system. Alterations of redox status have been shown in blood of patients with $\mathrm{EH}$ and ECa [45]. Tissues undergoing oncogenic transformation may acquire additional energy source with an increased synthesis of endogenous fatty acids [46]. The fatty acid metabolism may promote oxidative stress in hyperplastic tissue $[47,48]$. Antioxidant and anti-inflammatory APOE activity is genotype-dependent (E $2>$ E $3>$ E 4) [49]. Different mechanisms of the implementation of APOE antioxidant function are discussed: metal sequestration [50, 51], free radical scavenging activity of the region rich in positively charged amino acids [52], and binding and detoxifying of 4hydroxynonenal (HNE) [53].

E 2 allele has never been studied in relation to endometrial cancer, though syndromes and biochemical characteristics associated with E 2 allele are known to predispose to endometrial cancer. Increased endometrial cancer risk is observed in patients with insulin resistance/metabolic syndrome, hypertriglyceridemia, and obesity [54-57]. The adipose tissue is a very important source of endogenous estrogens in postmenopausal women. Estrogens produced in adipose tissue exhibit mitogenic activity on endometrial cells that leads to an increased risk of endometrial cancer [54]. Estrogens may induce oxidative stress by different mechanisms [58] and oxidative stress, in turn, leads to the excessive formation of semiquinones and quinones from catechol estrogens. Oxidation of catechol estrogens to semiquinones and then to quinones is a pathway that generates reactive oxygen species (ROS) such as hydroxyl radicals $\left({ }^{\circ} \mathrm{OH}\right)$ that can cause DNA damage and initiate cancer [59]. Cancer cells increase their production of mitochondrial ROS to further stimulate neoplastic transformation [60]. Oxidative stress and free radicals are important activators for apoptosis [61], and if cancer is already present, free radicals are important for apoptosis signals [62]. Tumor cells proliferate faster when oxidative stress is suppressed. It was shown that antioxidants may stimulate the growth of early tumors or precancerous lesions in high-risk populations [63]. In the current study, we observed that $\mathrm{E} 2$ allele with the highest antioxidant activity was more frequent in patients with concurrent occurrence of $\mathrm{EH}$ and ECa. These results support the increasing experimental data on the protective effects of the oxidative stress against further growth and malignization of precancerous lesions.

In the present assay we found that $A P O E \mathrm{E} 4$ allele was associated with $\mathrm{EH}$ and observed a protective effect of HFE rs429358 allele G against ECa. Both results failed to pass Bonferroni's correction for multiple statistical tests and may be only taken into account for future research directions. To the best of our knowledge, data about the role of $\mathrm{E} 4$ allele in hyperplasia and endometrial cancer are absent. Among other hormone-dependent cancers, it has been shown that $\mathrm{E} 4$ allele is a low-penetrant risk factor for breast cancer [64] and prostate cancer [65]. In large samples of longitudinally followed populations, shorter life expectancy was assumed in females due to non-sex-specific cancers, associated with E 4 allele [66]. HFE (high iron) is a major histocompatibility complex (MHC) class I-like gene. HFE protein regulates iron uptake into cells and is predominantly expressed in tissues involved in iron storage, such as hepatocytes and macrophages. Most individuals (80-90\%) affected by hemochromatosis (iron overload) are homozygous for the Cys282Tyr substitution. HFE variant His63Asp has a very low penetrance and mild expressivity for iron overload [67]. HFE Cys282Tyr variant allele is associated with breast cancer [68], colorectal cancer [69], and hepatocellular carcinoma [70]. A protective role of this variant was found against chronic myeloproliferative disease [71]. HFE His63Asp variant allele was more frequent in gastric cancer [72].

Our study has both limitations and strengths. The main limitations are the relatively low number of patients and unavailable data on the receptor status of the ECa. The important strengths are as follows. Our controls and all groups of cases have the same clinical and demographic characteristics. We selected a large control group and allele frequencies were very close to those found in other Caucasian populations. Statistical analyses included all main covariates important in regard to $\mathrm{EH}$ and ECa risk.

In summary, the role of functional SNPs in the COMT, $A P O E$, and HFE genes in EH and ECa was elucidated in Caucasians from Russian Federation. Current data provide, for the first time, strong evidence that $\mathrm{E} 2$ allele of the $A P O E$ gene is associated with concurrent occurrence of $\mathrm{EH}$ and ECa. These results are in line with known associations of this allele with diseases or traits predisposing to ECa, such as obesity, metabolic syndrome, and hypertriglyceridemia. Further studies with larger sample sizes and other populations are required to replicate our results.

\section{Abbreviations}

AIC: Akaike's Information Criterion

APOE: Apolipoprotein E (protein) 
APOE: Apolipoprotein E (gene)

BMI: Body mass index

COMT: Catechol-O-methyltransferase (protein)

COMT: Catechol-O-methyltransferase (gene)

CI: Confidence interval

ECa: Endometrial carcinoma (ECa)

EH: Endometrial hyperplasia

FIGO: The International Federation of Gynecology and Obstetrics

HFE: Hemochromatosis (protein)

HFE: Hemochromatosis (gene)

HRT: Hormone replacement therapy

OR: Odds ratio

ROS: $\quad$ Reactive oxygen species

SNP: Single nucleotide polymorphism.

\section{Conflict of Interests}

The authors declare no conflict of interests.

\section{Acknowledgment}

This work was supported by the Russian Foundation for Basic Research, Project 14-44-03072.

\section{References}

[1] A. Jemal, F. Bray, M. M. Center, J. Ferlay, E. Ward, and D. Forman, "Global cancer statistics," CA: Cancer Journal for Clinicians, vol. 61, no. 2, pp. 69-90, 2011.

[2] D. G. Gallup and R. J. Stock, "Adenocarcinoma of the endometrium in women 40 years of age or younger," Obstetrics and Gynecology, vol. 64, no. 3, pp. 417-420, 1984.

[3] H. J. Norris, F. A. Tavassoli, and R. J. Kurman, "Endometrial hyperplasia and carcinoma. Diagnostic considerations," The American Journal of Surgical Pathology, vol. 7, no. 8, pp. 839847, 1983.

[4] K. C. Podratz, A. Mariani, and M. J. Webb, "Staging and therapeutic value of lymphadenectomy in endometrial cancer," Gynecologic Oncology, vol. 70, no. 2, pp. 163-164, 1998.

[5] M. L. MacKintosh and E. J. Crosbie, "Obesity-driven endometrial cancer: is weight loss the answer?" BJOG: An International Journal of Obstetrics \& Gynaecology, vol. 120, no. 7, pp. 791-794, 2013.

[6] H. K. Vincent and A. G. Taylor, "Biomarkers and potential mechanisms of obesity-induced oxidant stress in humans," International Journal of Obesity, vol. 30, no. 3, pp. 400-418, 2006.

[7] K. M. Nieman, I. L. Romero, B. van Houten, and E. Lengyel, "Adipose tissue and adipocytes support tumorigenesis and metastasis," Biochimica et Biophysica Acta (BBA)-Molecular and Cell Biology of Lipids, vol. 1831, no. 10, pp. 1533-1541, 2013.

[8] A. D. Romano, G. Serviddio, A. de Matthaeis, F. Bellanti, and G. Vendemiale, "Oxidative stress and aging," Journal of Nephrology, vol. 23, supplement 15, pp. S29-S36, 2010.

[9] M. L. Hamilton, H. van Remmen, J. A. Drake et al., "Does oxidative damage to DNA increase with age?" Proceedings of the National Academy of Sciences of the United States of America, vol. 98, no. 18, pp. 10469-10474, 2001.

[10] I. Esinler, D. Aktas, M. Alikasifoglu, E. Tuncbilek, and A. Ayhan, "CYP1A1 gene polymorphism and risk of endometrial hyperplasia and endometrial carcinoma," International Journal of Gynecological Cancer, vol. 16, no. 3, pp. 1407-1411, 2006.

[11] M. Aban, M. Arslan, E. Tok, S. Tekes, T. Budak, and A. Altintas, "CYP17 genetic polymorphism in patients with endometrial hyperplasia and cancer," International Journal of Gynecological Cancer, vol. 16, no. 1, pp. 448-451, 2006.

[12] E. B. Morosova, A. B. Chukhlovin, N. V. Kulagina, N. V. Kipich, and A. A. Totolian, "Functional gene polymorphism of matrix metalloproteinase-1 is associated with benign hyperplasia of myo-and endometrium in the Russian population," Genetic Testing and Molecular Biomarkers, vol. 16, no. 9, pp. 1032-1037, 2012.

[13] G. L. Mutter and The Endometrial Collaborative Group, "Endometrial intraepithelial neoplasia (EIN): will it bring order to chaos?” Gynecologic Oncology, vol. 76, no. 3, pp. 287-290, 2000.

[14] FIGO Committee on Gynecologic Oncology, "FIGO staging for carcinoma of the vulva, cervix, and corpus uteri," International Journal of Gynecology \& Obstetrics, vol. 125, no. 2, pp. 97-98, 2014.

[15] T. I. Ivanova, T. V. Kondrashova, L. I. Krikunova et al., "The polymorphism of catechol-O-methyltransferase (COMT) and hemochromatosis (HFE) genes in the radiocontaminated regions residents with different chromosome aberration frequency," Biophysics, vol. 55, no. 6, pp. 1076-1084, 2010.

[16] J. H. Abramson, "WINPEPI updated: computer programs for epidemiologists, and their teaching potential," Epidemiologic Perspectives and Innovations, vol. 8, no. 1, article 1, 2011.

[17] X. Solé, E. Guinó, J. Valls, R. Iniesta, and V. Moreno, "SNPStats: a web tool for the analysis of association studies," Bioinformatics, vol. 22, no. 15, pp. 1928-1929, 2006.

[18] E. P. Hong and J. W. Park, "Sample size and statistical power calculation in genetic association studies," Genomics \& Informatics, vol. 10, no. 2, pp. 117-122, 2012.

[19] S. Shapiro, "Looking to the 21st century: have we learned from our mistakes, or are we doomed to compound them?" Pharmacoepidemiology and Drug Safety, vol. 13, no. 4, pp. 257265, 2004.

[20] M. Abal, J. Planaguma, A. Gil-Moreno et al., "Molecular pathology of endometrial carcinoma: transcriptional signature in endometrioid tumors," Histology and Histopathology, vol. 21, no. 2, pp. 197-204, 2006.

[21] G. Plataniotis, M. Castiglione, and ESMO Guidelines Working Group, "Endometrial cancer: ESMO clinical practice guidelines for diagnosis, treatment and follow-up," Annals of Oncology, vol. 21, supplement 5, pp. v41-v45, 2010.

[22] C. L. Trimble, J. Kauderer, R. Zaino et al., "Concurrent endometrial carcinoma in women with a biopsy diagnosis of atypical endometrial hyperplasia: a gynecologic oncology group study," Cancer, vol. 106, no. 4, pp. 812-819, 2006.

[23] T.-B. Zhou, "Signaling pathways of apoE and its role of gene expression in glomerulus diseases," Journal of Receptors and Signal Transduction, vol. 33, no. 2, pp. 73-78, 2013.

[24] A. Germeyer, E. Capp, F. Schlicksupp et al., "Cell-type specific expression and regulation of apolipoprotein D and e in human endometrium," European Journal of Obstetrics \& Gynecology and Reproductive Biology, vol. 170, no. 2, pp. 487-491, 2013.

[25] Y.-S. Wang, R. Cao, H. Jin et al., "Altered protein expression in serum from endometrial hyperplasia and carcinoma patients," Journal of Hematology and Oncology, vol. 4, article 15, 2011. 
[26] J. Huvila, A. Brandt, C. R. Rojas et al., "Gene expression profiling of endometrial adenocarcinomas reveals increased apolipoprotein E expression in poorly differentiated tumors," International Journal of Gynecological Cancer, vol. 19, no. 7, pp. 1226-1231, 2009.

[27] C. D. Hough, C. A. Sherman-Baust, E. S. Pizer et al., "Large-scale serial analysis of gene expression reveals genes differentially expressed in ovarian cancer," Cancer Research, vol. 60, no. 22, pp. 6281-6287, 2000.

[28] Y.-C. Chen, G. Pohl, T.-L. Wang et al., "Apolipoprotein E is required for cell proliferation and survival in ovarian cancer," Cancer Research, vol. 65, no. 1, pp. 331-337, 2005.

[29] K. H. Yu, A. K. Rustgi, and I. A. Blair, "Characterization of proteins in human pancreatic cancer serum using differential gel electrophoresis and tandem mass spectrometry," Journal of Proteome Research, vol. 4, no. 5, pp. 1742-1751, 2005.

[30] M. C. Venanzoni, S. Giunta, G. B. Muraro et al., "Apolipoprotein E expression in localized prostate cancers," International Journal of Oncology, vol. 22, no. 4, pp. 779-786, 2003.

[31] N. Oue, Y. Hamai, Y. Mitani et al., "Gene expression profile of gastric carcinoma: identification of genes and tags potentially involved in invasion, metastasis, and carcinogenesis by serial analysis of gene expression," Cancer Research, vol. 64, no. 7, pp. 2397-2405, 2004.

[32] K. Sakashia, F. Tanaka, X. Zhang et al., "Clinical significance of ApoE expression in human gastric cancer," Oncology Reports, vol. 20, no. 6, pp. 1313-1319, 2008.

[33] Y. Ito, T. Takano, and A. Miyauchi, "Apolipoprotein E expression in anaplastic thyroid carcinoma," Oncology, vol. 71, no. 5-6, pp. 388-393, 2007.

[34] J. A. R. Nicoll, E. Zunarelli, R. Rampling, L. S. Murray, V. Papanastassiou, and J. Stewart, "Involvement of apolipoprotein $\mathrm{E}$ in glioblastoma: immunohistochemistry and clinical outcome," NeuroReport, vol. 14, no. 15, pp. 1923-1926, 2003.

[35] Y.-S. Wang, R. Cao, H. Jin et al., "Altered protein expression in serum from endometrial hyperplasia and carcinoma patients," Journal of Hematology and Oncology, vol. 4, article 15, 2011.

[36] D. Chen, K. Yang, J. Mei, G. Zhang, X. Lv, and L. Xiang, "Screening the pathogenic genes and pathways related to DMBA (7,12-dimethylbenz[a]anthracene)-induced transformation of hamster oral mucosa from precancerous lesions to squamous cell carcinoma," Oncology Letters, vol. 2, no. 4, pp. 637-642, 2011.

[37] L. Larkin, L. M. Khachigian, and W. Jessup, "Regulation of apolipoprotein E production in macrophages (review)," International Journal of Molecular Medicine, vol. 6, no. 3, pp. 253258, 2000.

[38] S. Soeda, N. Nakamura, T. Ozeki et al., "Tumor-associated macrophages correlate with vascular space invasion and myometrial invasion in endometrial carcinoma," Gynecologic Oncology, vol. 109, no. 1, pp. 122-128, 2008.

[39] X.-F. Jiang, Q.-L. Tang, H.-G. Li et al., “Tumor-associated macrophages correlate with progesterone receptor loss in endometrial endometrioid adenocarcinoma," Journal of Obstetrics and Gynaecology Research, vol. 39, no. 4, pp. 855-863, 2013.

[40] D. Nguyen, P. Dhanasekaran, M. Nickel et al., "Molecular basis for the differences in lipid and lipoprotein binding properties of human apolipoproteins E3 and E4," Biochemistry, vol. 49, no. 51, pp. 10881-10889, 2010.

[41] H.-W. Liu, F. Zhang, P. Fan, H. Bai, J.-X. Zhang, and Y. Wang, "Effects of apolipoprotein e genotypes on metabolic profile and oxidative stress in south-west Chinese women with polycystic ovary syndrome," European Journal of Obstetrics Gynecology and Reproductive Biology, vol. 170, no. 1, pp. 146-151, 2013.

[42] T. A. Khan, T. Shah, D. Prieto et al., "Apolipoprotein E genotype, cardiovascular biomarkers and risk of stroke: systematic review and meta-analysis of 14, 015 stroke cases and pooled analysis of primary biomarker data from up to 60,883 individuals," International Journal of Epidemiology, vol. 42, no. 2, pp. 475492, 2013.

[43] L. Bertram, M. B. McQueen, K. Mullin, D. Blacker, and R. E. Tanzi, "Systematic meta-analyses of Alzheimer disease genetic association studies: the AlzGene database," Nature Genetics, vol. 39, no. 1, pp. 17-23, 2007.

[44] E. Campalani, M. H. Allen, D. Fairhurst et al., "Apolipoprotein E gene polymorphisms are associated with psoriasis but do not determine disease response to acitretin," British Journal of Dermatology, vol. 154, no. 2, pp. 345-352, 2006.

[45] S. Pejić, J. Kasapović, A. Todorović, V. Stojiljković, and S. B. Pajović, "Lipid peroxidation and antioxidant status in blood of patients with uterine myoma, endometrial polypus, hyperplastic and malignant endometrium," Biological Research, vol. 39, no. 4, pp. 619-629, 2006.

[46] V. Sebastiani, P. Visca, C. Botti et al., "Fatty acid synthase is a marker of increased risk of recurrence in endometrial carcinoma," Gynecologic Oncology, vol. 92, no. 1, pp. 101-105, 2004.

[47] E. O. Hileman, J. Liu, M. Albitar, M. J. Keating, and P. Huang, "Intrinsic oxidative stress in cancer cells: a biochemical basis for therapeutic selectivity," Cancer Chemotherapy and Pharmacology, vol. 53, no. 3, pp. 209-219, 2004.

[48] J. Hofmanovà, K. Souček, A. Vaculovà, and A. Kozubík, "Fatty acids in the modulation of reactive oxygen species balance in cancer," in Oxidants in Biology, G. Valacchi and P. A. Davis, Eds., pp. 129-153, Springer Science \& Business Media B.V., 2008.

[49] L. Jofre-Monseny, A.-M. Minihane, and G. Rimbach, "Impact of apoE genotype on oxidative stress, inflammation and disease risk," Molecular Nutrition \& Food Research, vol. 52, no. 1, pp. 131145, 2008.

[50] M. Miyata and J. D. Smith, "Apolipoprotein E allele-specific antioxidant activity and effects on cytotoxicity by oxidative insults and beta-amyloid peptides," Nature Genetics, vol. 14, no. 1, pp. 55-61, 1996.

[51] H. Xu, D. I. Finkelstein, and P. A. Adlard, "Interactions of metals and Apolipoprotein E in Alzheimer's disease," Frontiers in Aging Neuroscience, vol. 6, p. 121, 2014.

[52] T. Pham, A. Kodvawala, and D. Y. Hui, "The receptor binding domain of apolipoprotein $\mathrm{E}$ is responsible for its antioxidant activity," Biochemistry, vol. 44, no. 20, pp. 7577-7582, 2005.

[53] W. A. Pedersen, S. L. Chan, and M. P. Mattson, "A mechanism for the neuroprotective effect of apolipoprotein E: isoformspecific modification by the lipid peroxidation product 4 hydroxynonenal," Journal of Neurochemistry, vol. 74, no. 4, pp. 1426-1433, 2000.

[54] K. Lindemann, L. J. Vatten, M. Ellstrøm-Engh, and A. Eskild, "Serum lipids and endometrial cancer risk: results from the HUNT-II study," International Journal of Cancer, vol. 124, no. 12, pp. 2938-2941, 2009.

[55] L. Dossus, A. Lukanova, S. Rinaldi et al., "Hormonal, metabolic, and inflammatory profiles and endometrial cancer risk within the EPIC cohort-a factor analysis," The American Journal of Epidemiology, vol. 177, no. 8, pp. 787-799, 2013.

[56] A. Hirasawa, K. Makita, T. Akahane et al., "Hypertriglyceridemia is frequent in endometrial cancer survivors," Japanese 
Journal of Clinical Oncology, vol. 43, no. 11, Article ID hyt125, pp. 1087-1092, 2013.

[57] K. Esposito, P. Chiodini, A. Capuano, G. Bellastella, M. I. Maiorino, and D. Giugliano, "Metabolic syndrome and endometrial cancer: a meta-analysis," Endocrine, vol. 45, no. 1, pp. 28-36, 2014.

[58] R. E. White, R. Gerrity, S. A. Barman, and G. Han, "Estrogen and oxidative stress: a novel mechanism that may increase the risk for cardiovascular disease in women," Steroids, vol. 75, no. 11, pp. 788-793, 2010.

[59] E. Cavalieri and E. Rogan, "The molecular etiology and prevention of estrogen-initiated cancers: Ockham's Razor: pluralitas non est ponenda sine necessitate. Plurality should not be posited without necessity," Molecular Aspects of Medicine, vol. 36, no. 1, pp. 1-55, 2014.

[60] N. S. Chandel and D. A. Tuveson, "The promise and perils of antioxidants for cancer patients," The New England Journal of Medicine, vol. 371, no. 2, pp. 177-178, 2014.

[61] S. Rinaldi, F. Landucci, and A. R. de Gaudio, "Antioxidant therapy in critically septic patients," Current Drug Targets, vol. 10, no. 9, pp. 872-880, 2009.

[62] Z. Akan and A. I. Garip, "Antioxidants may protect cancer cells from apoptosis signals and enhance cell viability," Asian Pacific Journal of Cancer Prevention, vol. 14, no. 8, pp. 4611-4614, 2013.

[63] V. I. Sayin, M. X. Ibrahim, E. Larsson, J. A. Nilsson, P. Lindahl, and M. O. Bergo, "Antioxidants accelerate lung cancer progression in mice," Science Translational Medicine, vol. 6, no. 221, Article ID 221ra15, 2014.

[64] M. Saadat, "Apolipoprotein E (APOE) polymorphisms and susceptibility to breast cancer: a meta-analysis," Cancer Research and Treatment, vol. 44, no. 2, pp. 121-126, 2012.

[65] W. B. Grant, "A multicountry ecological study of risk-modifying factors for prostate cancer: apolipoprotein E epsilon4 as a risk factor and cereals as a risk reduction factor," Anticancer Research, vol. 30, no. 1, pp. 189-199, 2010.

[66] A. M. Kulminski, K. G. Arbeev, I. Culminskaya et al., "Age, gender, and cancer but not neurodegenerative and cardiovascular diseases strongly modulate systemic effect of the Apolipoprotein E4 allele on lifespan," PLoS Genetics, vol. 10, no. 1, Article ID e1004141, 2014.

[67] Y. Yang, C. Férec, and C. Mura, "SNP and haplotype analysis reveals new HFE variants associated with iron overload trait," Human Mutation, vol. 32, no. 4, pp. E2104-E2117, 2011.

[68] X. Liu, C. Lv, X. Luan, and M. Lv, "C282Y polymorphism in the HFE gene is associated with risk of breast cancer," Tumor Biology, vol. 34, no. 5, pp. 2759-2764, 2013.

[69] W. Chen, H. Zhao, T. Li, and H. Yao, "HFE gene C282Y variant is associated with colorectal cancer in Caucasians: a metaanalysis," Tumor Biology, vol. 34, no. 4, pp. 2255-2259, 2013.

[70] F. Jin, L.-S. Qu, and X.-Z. Shen, "Association between C282Y and $\mathrm{H} 63 \mathrm{D}$ mutations of the HFE gene with hepatocellular carcinoma in European populations: a meta-analysis," Journal of Experimental \& Clinical Cancer Research, vol. 29, no. 1, article $18,2010$.

[71] H. Andrikovics, N. Meggyesi, A. Szilvasi et al., "HFE C282Y mutation as a genetic modifier influencing disease susceptibility for chronic myeloproliferative disease," Cancer Epidemiology Biomarkers \& Prevention, vol. 18, no. 3, pp. 929-934, 2009.

[72] A. Agudo, C. Bonet, N. Sala et al., "Hemochromatosis (HFE) gene mutations and risk of gastric cancer in the european prospective investigation into cancer and nutrition (EPIC) study," Carcinogenesis, vol. 34, no. 6, pp. 1244-1250, 2013. 


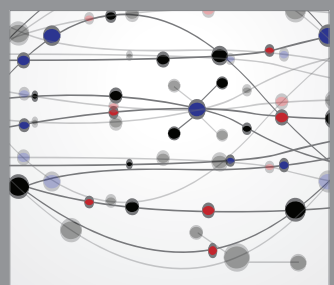

The Scientific World Journal
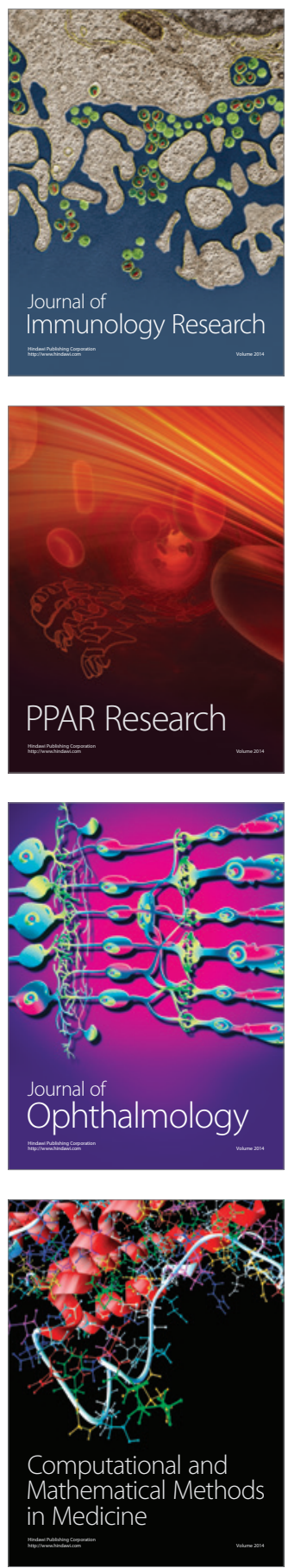

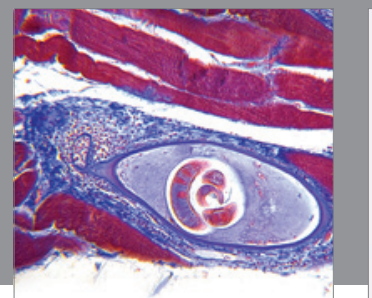

Gastroenterology

Research and Practice
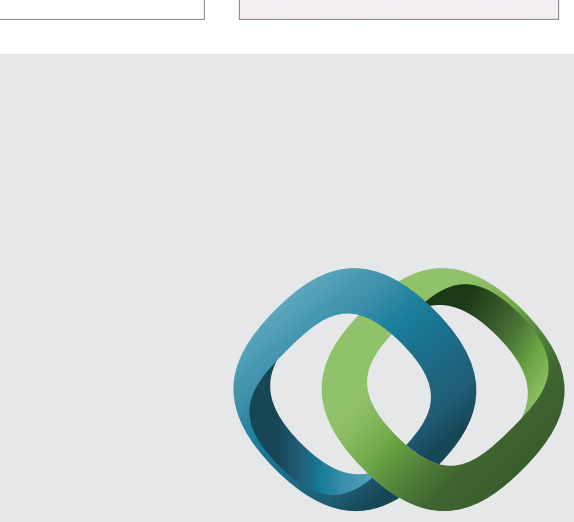

\section{Hindawi}

Submit your manuscripts at

http://www.hindawi.com
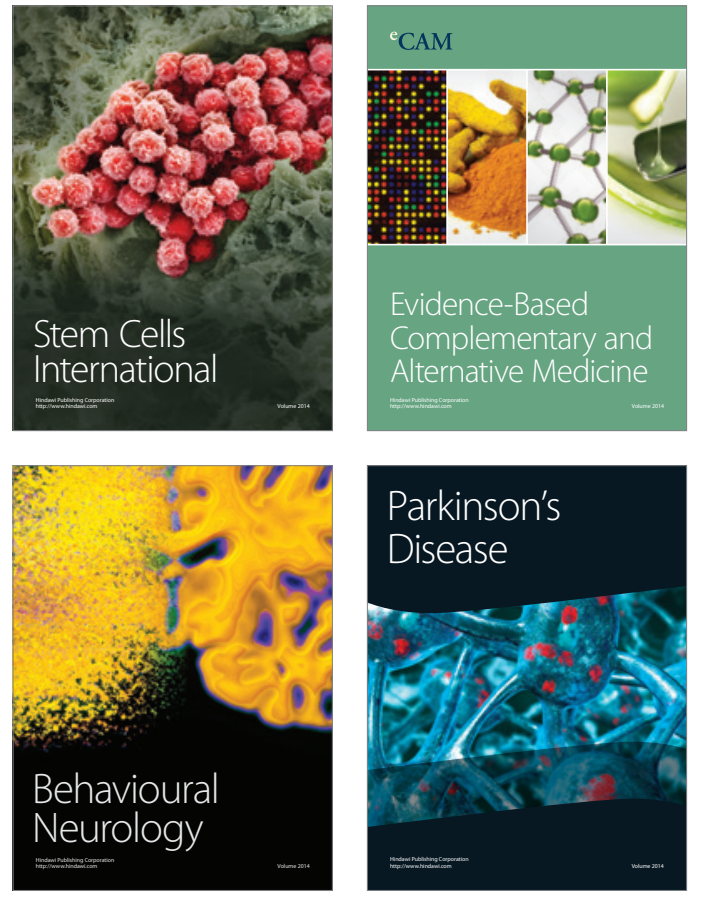
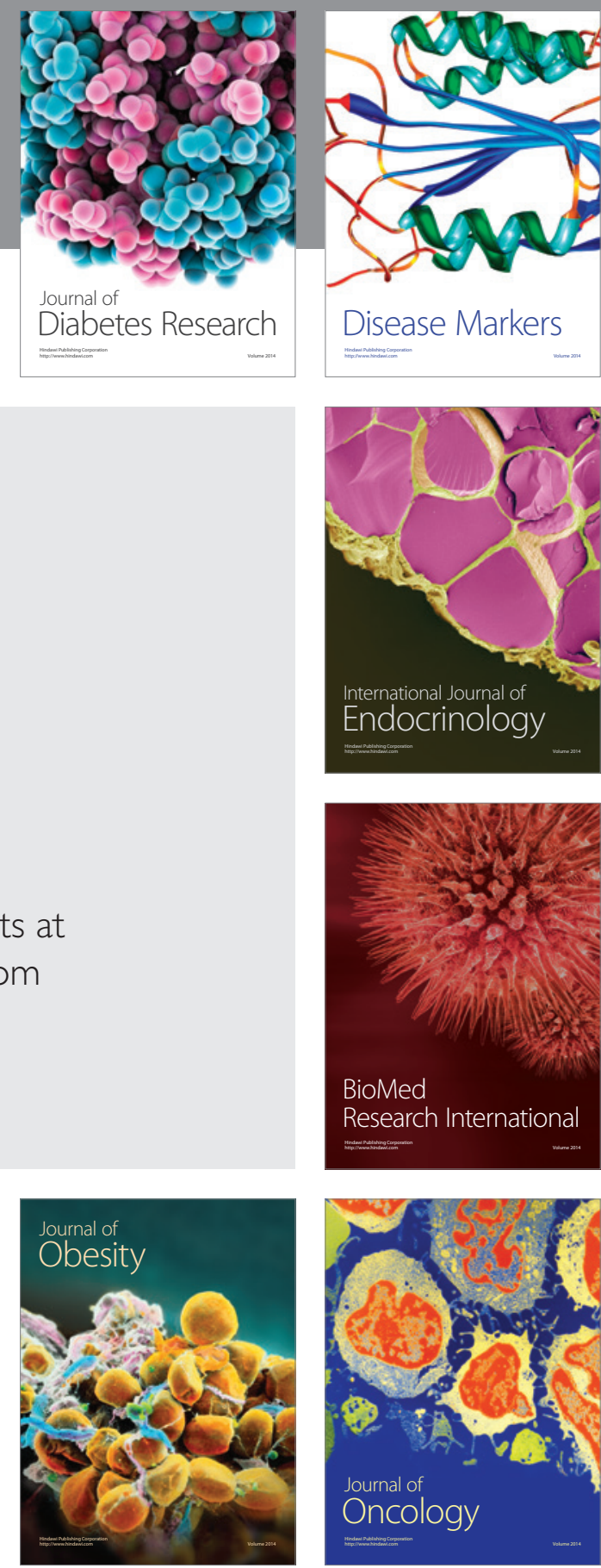

Disease Markers
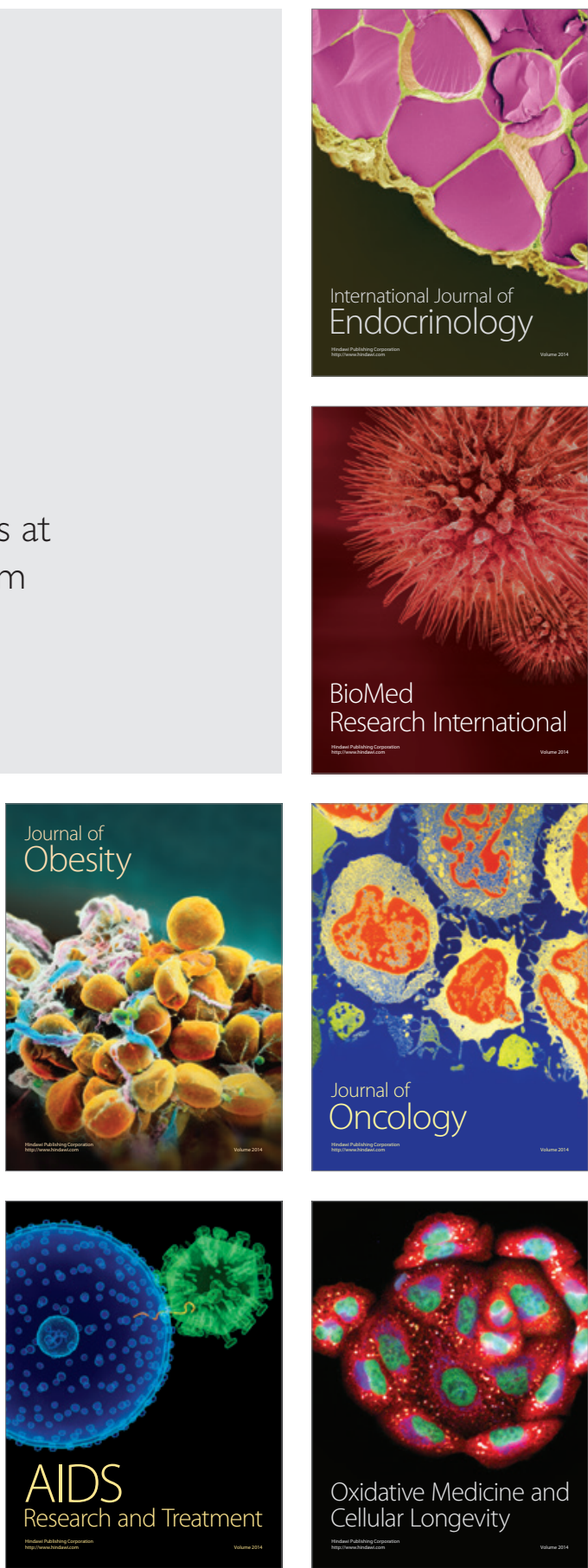